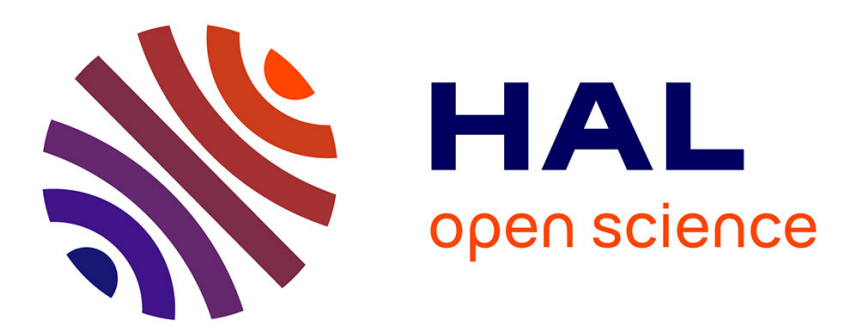

\title{
Suicidal ideation among French adolescents: Separation anxiety and attachment according to sex
}

Catherine Potard, Céline Combes, Florence Labrell

\section{To cite this version:}

Catherine Potard, Céline Combes, Florence Labrell. Suicidal ideation among French adolescents: Separation anxiety and attachment according to sex. Journal of Genetic Psychology, 2020, 181 (6), pp.470-488. 10.1080/00221325.2020.1822773 . hal-02976804

\section{HAL Id: hal-02976804 \\ https://hal.science/hal-02976804}

Submitted on 2 Nov 2020

HAL is a multi-disciplinary open access archive for the deposit and dissemination of scientific research documents, whether they are published or not. The documents may come from teaching and research institutions in France or abroad, or from public or private research centers.
L'archive ouverte pluridisciplinaire HAL, est destinée au dépôt et à la diffusion de documents scientifiques de niveau recherche, publiés ou non, émanant des établissements d'enseignement et de recherche français ou étrangers, des laboratoires publics ou privés. 
title: Suicidal ideation and affective insecurity during adolescence

Title : Suicidal ideation among French adolescents: Separation anxiety and attachment according to

\author{
Authors: C.Potard, C. Combes \& F. Labrell
}

Revue : The Journal of Genetic Psychology

\begin{abstract}
The present study explored the links between the quality of adolescents' attachment to their mother and their father, separation anxiety and suicidal ideation. Self-report questionnaires were completed by French adolescents $\left(n=455 ; M_{\mathrm{age}}=15.78\right.$ years, $\left.S D=1.61\right)$ to probe their attachment styles, separation anxiety (related to school phobia, a secure base, and family members), and suicidal ideation. Avoidantly attached adolescents displayed greater school phobia than securely attached adolescents. Female adolescents with an avoidant attachment to their father tended to report less fear related to family members than their secure counterparts. Male adolescents who were insecurely attached to their mother reported more separation anxiety than securely attached males. The structural models were significant for both boys and girls $\left(R^{2}=.38\right.$ and $\left..44, p<.001\right)$ with good fit indices. Mediation analyses revealed that separation anxiety partially mediated the negative effect of attachment to mother (especially alienation) on suicidal ideation for both girls and boys, and partially mediated the negative effect of attachment to father (especially alienation) on suicidal ideation for boys. These results support an individuated conception of attachment patterns, with a differential influence of dyadic relationships, and could provide a better understanding of adolescents' suicidal ideation.
\end{abstract}

Keywords: attachment; suicidal ideation; separation anxiety; adolescence

Page 3 of 41 
title: Suicidal ideation and affective insecurity during adolescence

\section{Introduction}

In Europe, suicidal ideation and behaviors in adolescence are a significant public health problem, as suicide represents the second leading cause of death among 15- to 25yearolds (WHO, 2014). In France, attempted suicides are especially high among the young (7.60 per 100 000; WHO, 2014). France has the third highest suicide rate in Europe. The prevalence of suicidal ideation in adolescence is approximately $30 \%$ (UNICEF, 2014). The continuum of suicidality runs from suicidal ideation or communication to attempting or completing suicide (Bridge et al., 2006; Miranda \& Shaffer, 2013). Suicidal ideation refers to thoughts and cognitions about ending one's life. A close link has been established between the severity of suicidal thoughts and the risk of attempting suicide (Czysz \& King, 2013; Lewinsohn et al., 1996; Reinherz et al., 2006).

\section{Separation-individuation process and parental attachment in adolescents}

Suicidality in adolescence needs to be understood in a developmental context (Daniel \& Goldston, 2009; Vander Stoep et al., 2009), and more specifically from a separationindividuation perspective (Blos, 1971; Demirdis \& Celik, 2013; Feldman \& Wilson, 1997; Meeus et al., 2005; Quintana \& Kerr, 1993). Separation-individuation refers to the development of independence and autonomy in the context of relationships with significant others, such as parents (Mattanah et al., 2004). According to Blos (1971), adolescents disinvest (i.e., disengage) from prior infantile representations of their parents, and search for new external and extrafamilial objects (i.e., independence; Kaplan, 1978; Kroger, 1998). During this ambivalent process, adolescents establish autonomous ego functions and, at the same time, maintain a sense of connectedness to their parents (i.e., no rupture, maintaining positive family bonds; Aquilino, 1997). It is a developmental challenge, as 
title: Suicidal ideation and affective insecurity during adolescence

adolescents' successful acquisition of autonomy is thought to determine their wellbeing and social adjustment (Allen \& Hauser, 1994; Holmbeck \& Leake, 1999; Lapsley \& Edgerton, 2002; Mattanah et al., 2004; Ponappa, et al., 2014). The conflictual dimension of parentadolescent relationships stems from difficulty achieving independence from one's mother or father (Boeninger et al., 2006; de Jong, 1992). When they encounter separation-individuation problems, adolescents may develop forms of either dysfunctional dependence, such as separation anxiety disorder or attachment anxiety, or dysfunctional independence, such as attachment avoidance (Kins et al., 2012).

Kaplan and Worth (1993) claimed that the psychological separation process and its inherent difficulties also need to be understood in terms of the developmental process of attachment in adolescence (e.g., Armsden \& Greenberg, 1987; Booth-LaForce et al., 2014; Hock et al., 2001; Kins et al., 2012). According to attachment theory (Bowlby, 1969; Bretherton, 1985), during infancy, the movement of detachment and the creation of new relationships are determined in part by the style of parental attachment (i.e., psychological security derived from relationships with significant others). Attachment theory suggests that attachment security derives from children's sense that the attachment figure is available or accepting when needed, and supports autonomy, exploration, and individuation (Ainsworth, 1979; Bowlby, 1969). Conversely, an insecure attachment style characterizes people who are insensitive, inconsistent, or have had abusive parenting experiences. Attachment security in adolescence can be defined as a lasting affectionate bond with parents, based on general feelings of security, trust, and positive communication (Armsden \& Greenberg, 1987). Once an internal working model has been established in infancy, a person tends to perceive future events through the filter of that model. Finally, some dysfunctional parenting behaviors lead to specific forms of insecure (avoidant or ambivalent) attachment (Koehn \& Kerns, 2018).

Unresponsive and rejecting parenting leads to avoidant attachment, while inconsistent Page 5 of 41 
title: Suicidal ideation and affective insecurity during adolescence

parenting in terms of providing warmth and emotional and autonomy support leads to ambivalent attachment (for a recent synthesis, see Koehn \& Kerns, 2018). Previous studies have established that attachment is relatively stable from childhood to adolescence (e.g., Jones et al., 2018).

Children with a secure attachment style should be comfortable with both separation and intimacy renegotiation in adolescence (Groh et al., 2014; Scharf et al., 2004). As far as we know, very few studies have empirically tested this hypothesis (Mayseless et al., 1996; Mayseless \& Scharf, 2009). These have reported that secure attachment is characterized by higher psychological independency from parents, and insecure attachment by greater dependency (Ponappa et al., 2014). These initial results suggested that children who have internalized positive mental representations of parents can more successfully resolve the second individuation process in adolescence (Holmbeck \& Leake, 1999).

\section{Parental attachment and suicidality in adolescents}

Suicidality among young people should be understood in terms of a psychological separation process and the parent-adolescent relationship. Research has underlined the importance of parental bonds in suicidal symptomatology in the transitional period between childhood and adulthood (Gouveia-Pereira et al., 2014; Lobo Prabhu et al., 2010). For example, studies have found that a negative father-child relationship is an especially significant risk factor for suicidal behavior in adolescents (Cero \& Sifers, 2013; Sheftall et al., 2013). These initial results are encouraging for understanding adolescent suicidality in the context of family relationships (Lobo Prabhu et al., 2010), even if attachment in adolescence has received less empirical investigation.

Previous research has also highlighted significant relations between the quality of attachment (e.g., insecure attachment) and internalizing symptoms (for a review, see Groh et al., 2012), such as suicidal behaviors (e.g., de Jong, 1992; Frey et al., 2006; Stepp et al., 2010; 
title: Suicidal ideation and affective insecurity during adolescence

Zortea et al., 2019) or different types of anxiety (e.g., Achtergrade et al., 2015; Colonnesi et al., 2011) in adolescence. Insecure attachment, especially ambivalent attachment, was found to be significantly associated with a higher risk of suicidal ideation and attempts in a clinical sample of adolescents (Adams et al., 1996; Lessard \& Moretti, 1998; Sheftall et al., 2013), while Manassis (2001) theorized that the insecure children display different types of anxiety: social phobia for avoidant and disorganized children, and separation anxiety for ambivalent children. Moreover, Roberto et al. (2009) suggested that adolescent satisfaction with the mother or father is related to attachment anxiety. Attachment anxiety is characterized by a strong desire for closeness in relationships and intense fear of rejection and abandonment (Jones et al., 2014).

\section{Parental attachment and separation anxiety in adolescents}

As mentioned above, psychological separation from one's parents constitutes a major life transition and contributes to the construction of autonomy during adolescence (Beyers et al., 2003; Koepke \& Denissen, 2012; Kroger, 1998). This transition can be viewed as an autonomy process, both for adolescents and their parents (Frank et al., 1990; Hock et al., 2001; Kins et al., 2012). In this context, adolescents can experience separation anxiety. Separation anxiety was defined by Levine and colleagues (1986) as having strong fears of losing contact with significant others, whether these feared separations are actual or perceived. It has been established that adolescents with higher separation anxiety exhibit fear of loss, social maladjustment, anxiety, and insecurity (e.g., Eliezer, 2012; Hock, 2001; Kins, 2011). Here, worries predominantly concern separation (or the possibility of being away) from attachment figures, as well as events befalling them (APA, 2013). A recent study underlined that individuals with an ambivalent attachment style tend to have higher levels of separation anxiety (Mabilia et al., 2019). However, the effect of separation anxiety on suicidality remains unclear. Some studies have suggested that separation anxiety is associated 
title: Suicidal ideation and affective insecurity during adolescence

with higher suicidal ideation (Gould et al., 1998; Strauss et al., 2000) and attempts (Gould et al., 1998), but others have failed to find any link with suicide attempts (Strauss et al., 2000) or, more broadly, with suicide-related behaviors (Hill et al., 2011) in clinical adolescent samples. To our knowledge, no studies have specifically investigated the role of separation anxiety role in suicidality in a nonclinical sample.

\section{Role of fathers' and mothers' attachment styles}

Regarding attachment relationships in adolescence, surprisingly little research has examined the differential influence of attachment to mother versus father on adolescent wellbeing or included assessments of both mothers and fathers. Father-child and mother-child attachments seem to have the same influence, although there have been very few studies of the former (Brumariu \& Kerns, 2010a). This lack of knowledge is due to the fact that the majority of attachment research has focused on attachment to mother, minimizing the fathers' contribution to attachment.

Furthermore, most authors have failed to consider the fact that patterns of interaction in family relationships depend on the sex of both the parent and the adolescent (Hoeve et al., 2011; Russel \& Saebel, 1997). For example, studies have shown that girls report more attachment security with mothers and fathers during adolescence than boys do, although these conclusions are controversial (Ruhl et al., 2015). According to Steinberg (1987) the separation-individuation process would be better described if four parent-adolescent dyads were taken into account: boys versus girls, each in relation to mothers versus fathers. The development of autonomy follows different pathways for girls and boys, especially in adolescence (Geuzaine et al., 2000; Sandhu, 2014; Stolz et al., 2005): for girls, emotional and cognitive processes serve as a means of disengaging themselves from their parents, whereas for boys, they serve as a means of maintaining relationships with them (Eliezer et al., 2012; Geuzaine et al., 2000). 
title: Suicidal ideation and affective insecurity during adolescence

\section{The present study}

Although some attachment-based family therapy for suicidal adolescents exists (e.g., Ewing et al., 2015), relatively few empirical studies of adolescents' suicidal thoughts have specifically focused on attachment relationships, separation anxiety, or parent-adolescent dyads. The aim of the present study was thus to understand suicidal ideation as a potential way for an adolescent to express the failure of the autonomy process. Suicide can be conceptualized as a response to loss, separation, or abandonment-separation disturbances (Feldman \& Wilson, 1997). Furthermore, difficulty with the second process of separationindividuation, expressed by separation anxiety, may be related to insecure attachment and suicidality signs and symptoms during adolescence (see Fig. 1). Attachment status may also moderate the effect of separation distress. We therefore set out to test how separation anxiety mediates the relationship between the quality of attachment and suicidal ideation in a sample of French adolescents. More specifically, we hypothesized that both attachment to mother $(\mathrm{H} 1)$ and attachment to father $(\mathrm{H} 2)$ have direct effects on suicidal ideation, and that these direct effects are mediated by separation anxiety (H3). Given previous research, it seemed appropriate to use dyads (same-sex and opposite-sex parent-adolescent dyads) to consider suicidal ideation in relation to attachment and family dynamics. First, we tested whether the style of attachment to father or mother and separation anxiety significantly explained suicidal ideation, considering girls and boys separately. Second, we tested whether separation anxiety mediated the links between parental attachment and level of suicidal ideation, again considering girls and boys separately.

Please insert Figure 1 about here

\section{Methods}

\section{Participants}

Page 9 of 41 
title: Suicidal ideation and affective insecurity during adolescence

After excluding students with three or more missing values on the questionnaires $(n=$ 56), our sample included 455 participants: $68.6 \%$ were girls $(n=312)$ and $31.4 \%$ were boys ( $n=143$ ). Participants were French adolescents aged 12.0-18.0 years, with a mean age of 15.78 years $(S D=1.61)$. Boys and girls differed significantly on age $\left(M_{\mathrm{age}}=15.69, S D=1.60\right.$ for girls, and $M_{\mathrm{age}}=16.07, S D=1.62$ for boys, $\left.t(453)=-2.027, p=.04\right)$. School levels were as follows: middle school $(n=194,42.6 \%)$, high school $(n=189,41.5 \%)$, and first year of university $(n=72,15.82 \%)$. The majority of the adolescents sampled lived in urban areas $(53.70 \%, n=245), 14.8 \%(n=67)$ in peri-urban areas, and $31.5 \%(n=143)$ in rural areas.

In our sample, $1.2 \%(n=5)$ of adolescents reported that for various reasons (e.g., death, family breakdown, unknown mother or father), they had no contact with their father, and $.2 \%(n=1)$ reported that they had no contact with their mother. These adolescents did not complete the attachment measure for the absent parent. As parental death was a potential bias, only students whose parents were both still alive were included in our study.

\section{Instruments}

Participants completed three measures of specific psychological constructs with the following self-report questionnaires:

Inventory of Parent and Peer Attachment. Quality of attachment to each parent was measured using the French version of the Inventory of Parent and Peer Attachment (IPPA; Vignoli \& Mallet, 2004). This measure assesses three aspects of attachment: Trust (10 items), Communication (9 items), and Alienation (6 items). Trust refers to the adolescents' trust that parents understand and respect their needs and desires, Communication assesses the extent and quality of verbal communication, and Alienation refers to adolescents' feelings of anger and interpersonal alienation in attachment relationships with their parents. Respondents rate each item on a 5-point scale ranging from 1 (Never true) to 5 (Always true). A total attachment security score is computed by summing the Trust and Communication subscores 
title: Suicidal ideation and affective insecurity during adolescence and subtracting the Alienation subscore. Vivona (2000) proposed an attachment style classification, making a distinction between secure, avoidant and ambivalent insecure styles. Individuals with higher scores on Alienation than on Trust or Communication are classified as avoidant, and those with lower scores on Trust than on Communication or Alienation are classified as ambivalent (Guarnieri et al., 2010). Although the IPPA was designed to obtain continuous ratings of each of the three attachment patterns, it can also be used as a categorical measure of attachment. In the present study, internal consistency (alpha) coefficients for the IPPA's three subscales ranged from .86 to .91 . Cronbach's alpha coefficients for Trust, Communication, and Alienation were $.92, .86$, and .70 for mothers, and $.91, .84$, and .68 for fathers.

Separation Anxiety Symptom Inventory (SASI; Brandibas et al., 2010). Participants completed the SASI, a 15-item self-report measure of separation anxiety symptoms. It can be used clinically to identify intrusive anxious symptomatology and difficulties in parent-child relationships. The SASI consists of three subscales: 1) School phobia, 2) Distress at being away from a secure base, and 3) Fear of harm befalling family members. The items are each rated on a Likert scale ranging from 0 (I never had this feeling) to 3 (This feeling occurred very often) and are summed to yield a total score. Higher scores indicate a higher level of anxiety. The SASI is a valid measure of separation anxiety for the developmental periods of mid-to-late adolescence. In the present study, Cronbach's alpha showed good internal consistency $(\alpha=.73$ to .86$)$.

The French version of the Suicidal Ideation Questionnaire (SIQ-Fr; Potard et al., 2014). This is a self-report measure of specific thoughts and cognitions about suicide and death during the past month. Each of its 30 items is rated on a 7-point scale ranging from 0 (Never had any thoughts) to 6 (Almost every day). Each item deals with a specific suicidal thought (e.g., "I thought about how others would feel if I killed myself", "I thought that 
title: Suicidal ideation and affective insecurity during adolescence

killing myself would solve my problems"). It was not designed to predict suicide, but to identify a broader range of individuals who have thoughts of death. Total scores range from 0 to 180 , with higher scores indicating more severe suicidal ideation. This scale has good psychometric properties (Potard et al., 2014). In our study, Cronbach's alpha was .94.

\section{Procedure}

After obtaining the permission of the school and university administrators, and the informed consent of the students (or their parents if they were aged under 18 years), we emailed individual invitations with links to the questionnaires in the form of an online survey. All the data were collected via the self-administered questionnaires. We explained the procedure for each questionnaire, emphasizing the confidentiality and anonymity of the data. The response rate was 68.3 percent for female adolescents and 54.8 percent for male adolescents.

\section{Statistics}

We performed Student's $t$ and chi-squared tests to compare the girls and boys on their group means for the different measures used in this study. We then assessed the links between students' attachment to their mother and to their father (Trust, Communication, Alienation) and separation anxiety (School phobia, Distress at being away from a secure base, and Fear of harm befalling family members) in suicidal ideation using Pearson correlation coefficients. We used analyses of variance (ANOVAs) to compare attachment style (categorical variable), suicidal ideation, and separation anxiety separately for each sex. When ANOVAs yielded significant results, we ran Bonferroni post hoc comparisons to test the group contrasts (between secure, ambivalent and avoidant attachment). Finally, we conducted a mediation analysis using partial least-squares structural equation modeling (consistent PLS-SEM) for latent variable analysis with a bias-corrected nonparametric percentile bootstrap method. Direct and indirect effects were tested, based on 5000 bootstrap samples with $95 \%$ confidence 
title: Suicidal ideation and affective insecurity during adolescence

intervals. To demonstrate the adequacy of the PLS model, high $R^{2}$ and significant structural paths have to be demonstrated. The bootstrap procedure provides $t$ values of the path coefficient in the model and indicates whether the path is statistically significant $(t>1.96$ for two-tailed tests; Hair et al., 2017, 2018).We used three other suggested fit indices (Leguina, 2013): variance inflation factor (VIF), effect sizes $\left(\mathrm{f}^{2}\right)$, cross-validated redundancy $\left(\mathrm{Q}^{2}\right)$, and variance accounted for (VAF). The standardized root mean square residual (SRMR) and the normalized fit index (NFI) were also examined. Statistical analyses were carried out using SPSS $^{\circledR}$ version 23 and SmartPLS ${ }^{\circledR}$ version 3. We adopted the conservative strategy of only considering coefficients that were statistically significant at $p<.05$.

\section{Results}

\section{Relations between attachment, separation anxiety, and suicidal ideation}

The distribution of maternal and paternal attachment styles in our sample is shown in Table 1. The chi-squared test showed nonsignificant differences in both male and female adolescent groups on style of attachment to mother $\left(\chi^{2}=1.524, p=.467\right)$, and a significant difference on style of attachment to father $\left(\chi^{2}=6.869, p<.05\right)$. Table 2 shows mean scores, standard deviations and sex differences on suicidal ideation, attachment and separation anxiety scores.

Please

insert Table 1 about here

Table 2 also reports correlation coefficients between the dimensions of separation anxiety, attachment to each parent, and suicidal ideation scores. All correlations were significant, for both sexes, with $r=-.25$ to $.46, p<.001$ for girls, and $r=.20, p<.05$ to $-.49, p$ $<.001$ for boys. 
title: Suicidal ideation and affective insecurity during adolescence

Concerning the correlations between separation anxiety scores and attachment dimensions, for girls they were significant for Trust $(r=-.16, p<.01$ for maternal trust; $r=$ $.19, p<.001$ for paternal trust) and Alienation $(r=.23, p<.001$ for maternal alienation; $r=$ $.17, p<.01$ for paternal alienation). Negative correlations were also found between paternal communication and Fear of harm befalling family members $(r=-.16, p<.01)$ and School phobia $(r=-.13, p<.05)$. For boys, School phobia was significantly correlated with all paternal and maternal attachment dimensions (with $r=-.40-.33, p<.01$ ). For boys only, Distress at being away from a secure base was linked to Alienation $(r=.29, p<.01$ for maternal alienation; $r=.22, p<.05$ for paternal alienation).

\section{Comparisons between suicidal ideation and separation anxiety scores according to attachment style}

To determine differences between attachment styles on suicidal ideation and separation anxiety scores, we ran separate ANOVAs for girls and boys. Means and standard deviations are presented in Table 3. Contrasted group validity was investigated by comparing the SIQ-Fr and SASI scores of secure, ambivalent and avoidant adolescents, with post hoc comparisons indicating significant differences between groups. The SIQ-Fr score was significantly higher among the ambivalent and avoidant adolescents than among Secure adolescents. With respect to separation anxiety, among the sample of girls, a significant ANOVA was found for School phobia and attachment to mother, and a trend toward significance for attachment to father: adolescents with an insecure (avoidant) style had a higher score than adolescents with secure attachment (see Table 3 for details). In addition, for attachment to father, we noted a trend toward a significant difference between secure and avoidant girls on Fear of harm befalling family members. Female adolescents with an avoidant attachment to father tended to have higher score on this subdomain than secure girls. Boys with insecure (ambivalent or avoidant) attachment to their father scored significantly 
title: Suicidal ideation and affective insecurity during adolescence

higher on School phobia than the secure group. For maternal attachment, only avoidant adolescents scored significantly higher on School phobia than secure adolescents. Finally, male adolescents with insecure (ambivalent or avoidant) attachment to mother scored significantly higher on Distress at being away from a secure base than those in the secure group.

insert Table 3 about here

\section{Examination of mediating effects}

The structural model was assessed in terms of the collinearity among the set of constructs, coefficient of determination ( $R^{2}$ adjusted value), significance of path coefficients, effect size $\left(\mathrm{f}^{2}\right)$, and predictive relevance $\left(\mathrm{Q}^{2}\right)$. First, we checked the structural model for collinearity issues, by examining the VIF values of all the sets of predictor constructs in the structural model. The VIF values for the set of independent variables on suicidal ideation ranged from 1.09 to 3.00 for girls and from 1.05 to 2.52 for boys, and were below the cut-off threshold of 5 for multicollinearity (Hair et al., 2017, 2018).

Figures 2 and 3 shows the adjusted $R^{2}$ values of suicidal ideation and separation anxiety, explaining $39 \%$ and $10 \%$ (for girls) and $44 \%$ and $34 \%$ (for boys) of the variance. Falk and Miller (1992) proposed a value of .10 as the minimum acceptable level, and $R^{2}$ values were above this threshold for all the endogenous latent variables. Chin (1998) classified $R^{2}$ levels as weak (.19), moderate (.33), or substantial (.67). The path analysis diagram is also provided in Figures 2 and 3. The significance of path coefficients was examined by performing the nonparametric bootstrapping procedure of 5000 resamples, as recommended by Hair et al. $(2017,2018)$. Classically, a standardized $\beta$ coefficient below .20 is considered 
title: Suicidal ideation and affective insecurity during adolescence

nonsignificant (Chin, 1998). For girls, attachment to mother was significantly positively related to suicidal ideation $(\beta=.28, t=2.18, p<.05)$ and anxiety separation $(\beta$

$=.30, t=2.58, p<.01)$. Attachment to father was significantly negatively related to suicidal ideation $(\beta=-.25, t=1.97, p<.05)$, but not to separation anxiety $(\beta=-.04, t=.72, n s)$. It should be noted that the standardized coefficients from attachment to father for girls have a negative value towards Separation Anxiety and Suicidal Ideation (see Figure 2), while those of attachment to the mother (girls and boys) and to father (boys) are positive. This is due to the fact that, in the first case, the attachment is one of good quality (cf. the values of Trust and Communication), contrary to what happens in the latter situations (cf. the values of Alienation). The attachment dimensions that contributed the most were Alienation for maternal attachment, and Trust for paternal attachment. The relationship between separation anxiety and suicidal ideation was significant $(\beta=.31, t=2.74, p<.01)$.

For boys, attachment to mother was nonsignificantly related to suicidal ideation $(\beta=$ $.14, t=1.59, n s)$, but significantly positively related to separation anxiety $(\beta=.39, t=3.54, p$ $<.001)$. Attachment to father was significantly related to both suicidal ideation $(\beta=.24, t=$ $1.98, p<.05)$ and separation anxiety $(\beta=.25, t=1.98, p<.05)$. Alienation was the dimension that contribute the most for both maternal and paternal attachment.

As an extra test, we examined effect size $\left(\mathrm{f}^{2}\right)$ and predictive relevance $\left(\mathrm{Q}^{2}\right)$. The $\mathrm{f}^{2}$ values for each relationship are summarized in Table 4. These values exceeded the minimum threshold of .02 recommended by (Chin, 1998, 2010). In addition, to assess the model's predictive capability, we performed a blindfolding procedure to report the value of $\mathrm{Q}^{2}$ (Chin, 1998, 2010). The $\mathrm{Q}^{2}$ values for suicidal ideation and separation anxiety were .32 and .03 for girls, and .20 and .06 for boys, suggesting that the model had predictive relevance. According 
title: Suicidal ideation and affective insecurity during adolescence

to Fornell and Cha (1994), values above zero for $\mathrm{Q}^{2}$ suggest that a model has reasonable predictive capability. The model presented a good fit, as the SRMR was .08 for girls and .10 for boys, close to the recommended values of .08 (Hu \& Betler, 1999) and .10 (Williams et

al., 2009). The NFI was calculated to evaluate the global model, yielding values of .85 for girls and .72 for boys. NFI values above .90 are considered acceptable (Byrne, 2013).

To test the mediation effect of separation anxiety, we applied two-step bootstrapping procedures (Chin, 2010). First, we assessed the links between attachment to mother or father, and suicidal ideation without the mediator variable (see "Direct effects without mediator" section of Table 5). Second, we added separation anxiety as the mediator variable and computed the two coefficients of attachment and suicidal ideation. Table 5 shows that the indirect effect was significant in our mediation model, excepted for girls' paternal attachment. VAF values, which indicate the size of the indirect effect in relation to the total effect, were .31 and .37 for girls' and boys' attachment to mother, and .59 for boys' attachment to father. VAF values between .20 and .80 indicate partial mediation (Hair et al., 2017), which was the case in our models.

\section{Discussion}

Adolescents frequently think about death, sometimes constructively. Suicidal ideation is not necessarily emblematic of a morbid process, notably when it remains externalized and is not associated with acting-out strategies. In general, it reflects a malaise or psychological distress. Given the high rates of teenage suicide in France (7.60 per 100 000; WHO, 2014), it is particularly important to have a better understanding of parent-child relationship factors that may trigger acute suicidal ideation. The present study examined the relationship between security of attachment and level of separation anxiety in the context of 
title: Suicidal ideation and affective insecurity during adolescence

adolescent suicidal ideation. By examining styles of attachment to both mothers and fathers, it is possible to investigate whether the sex of the parent and the adolescent moderates the link between security and suicidal ideation during the second separation-individuation process in adolescence. One of the primary aims of the present study was to examine whether separation anxiety mediates the relationship between parental attachment and adolescent suicidal

ideation. As predicted, we found that insecure attachment was related to high levels of suicidal ideation in both boys and girls, but these levels differed between attachment to mother and attachment to father. We also found a strong association between insecure attachment relationships and separation anxiety, especially the School phobia dimension. Finally, the results of path analyses showed that separation anxiety partially mediated the relations between parental attachment and adolescent suicidal ideation. Results also showed that mediation pathways differed according to sex of adolescents.

\section{Relationships between attachment style, suicidal ideation and separation anxiety according} to sex

As anticipated, we found a stronger connection in our participants between being insecure and suicidal ideation, in line with the literature on adolescent suicidality (Cero et al., 2013; Lobo Prabhu et al., 2010; Sheftall et al., 2013). Adopting a categorical approach to attachment (three styles of attachment), we found that avoidant adolescents exhibited significantly higher suicidal ideation than either ambivalent or secure adolescents, for parentadolescent relationships of both sexes. In turn, ambivalent adolescents expressed higher suicidal ideation than secure adolescents. These findings were confirmed by adopting a dimensional approach to attachment. In our study, this association was especially high for maternal Alienation in both girls and boys. In boys specifically, paternal Trust and paternal 
title: Suicidal ideation and affective insecurity during adolescence

Alienation were also highly related, bearing in mind that the Trust dimension measures the degree of respect and mutual understanding in the attachment relationship, while the Alienation dimension evaluates feelings of anger and interpersonal alienation (Guarnieri et al., 2010; Gullone \& Robinson, 2005). First, it is important to note that these preliminary results provide empirical support for the theoretical assumption of an association between insecure attachment and internalizing symptoms in early childhood, and extend it to adolescents (e.g.,

Milan et al., 2013). Hypothesizing suicidal ideation in adolescent development in the context

of family relationships is important: attachment to parents continues to be a crucial source of support for adolescents during the process of individuation. Second, these results highlight specific mother-daughter/son and father-son/daughter associations. Contrary to the classic maternalistic perspective (see Lamb, 1974), paternal attachment seems to be just as important as maternal attachment. Fathers are salient figures in the lives of adolescents, and paternal attachment contributes to the latter's psychological wellbeing (e.g., Duchesne \& Ratelle, 2014; Flouri \& Buchanan, 2003). Finally, these results highlight the relevance of a multidimensional measure (e.g., trust, communication, alienation dimensions) that takes the complexity of the attachment system into account (Gullone et al., 2005).

Regarding separation anxiety, our findings showed that more insecurely attached adolescents reported more separation anxiety, and more securely attached adolescents had lower levels of separation anxiety across all the dimensions. More specifically, our results indicated that avoidantly attached adolescents, both girls and boys, exhibited greater School phobia than securely attached adolescents. These findings were observed for both maternal and paternal attachment, and are consistent with Bowlby's notion of pseudophobia (1976, p. 258) whereby school phobia is determined by separation anxiety. Contemporary studies emphasize 
title: Suicidal ideation and affective insecurity during adolescence

that more securely attached children report lower levels of social anxiety and school anxiety (Brumariu \& Kerns, 2010b), and fewer anxiety disorders in emerging adulthood in the long term (Schimmenti \& Bifulco, 2015). From an ethological perspective, this reflects an avoidance associated with a search for help and reassurance, where children actively seek out figures in their environment who will afford them security and protection (mother, father). For insecure adolescents, going to school represents a major separation from the family nucleus. In our study, avoidantly attached adolescents seemed to express more separation complaints linked to School phobia (e.g., not wanting to go to school, displaying physical symptoms before going to school, being very tense before going to school). By

Page 19 of 41

contrast, Manassis (2001) postulated that the ambivalent attachment style is associated with separation anxiety in childhood. This may simply be due to the differential effect of parentchild relationships in an adolescent context. Moreover, the literature solely concerns attachment to mother (e.g., Brumariu et al., 2010b).

In this context, our results suggest it is important to consider both parent and child sex when exploring specific associations. Girls with an avoidant attachment to father had a tendency to report lower Fear of harm befalling family members than secure girls. They tended to minimize the importance of connection to and support from the paternal attachment figure (Ruhl et al., 2015). Teenage boys who were insecurely attached to their mother exhibited more separation anxiety than their securely attached counterparts. We also found that adolescents with insecure (avoidant or ambivalent) versus secure attachment to their mother differed on Distress at being away from a secure base. These preliminary results emphasize the specificity of links between different attachment styles and dimensions of separation anxiety according to sex. An avoidant relationship between father and daughter 
title: Suicidal ideation and affective insecurity during adolescence

seems to deactivate Fear of harm befalling family members, while insecure (especially ambivalent) attachment between mother and son seems to exacerbate Distress at being away from a secure base. This suggests that boys with avoidant attachment to mother and father may be particularly at risk of separation anxiety symptoms, in contrast to those with other types of attachment.

Role of separation anxiety in the relationship between attachment and suicidal ideation: a mediational perspective

According to Bowlby's theory, secure attachment plays a decisive role in the adolescent's process of individuation (Hock et al., 2001; Kaplan al., 1993; Kins et al., 2012), and the quality of current attachment relationships may play a crucial role in psychological wellbeing in the long term (e.g., suicidal ideation during adolescence). Understanding the

affective and emotional factors that lead adolescents to think about suicide will determine whether separation anxiety and/or the quality of adolescent-parent relationships are clinical markers of strong susceptibility to suicidal ideation.

As we indicated earlier, the present study tested the hypotheses that the quality of adolescent-parent attachment is linked to separation anxiety (H1 and H2) and suicidal ideation (H3). Our findings confirmed these hypotheses: attachment emerged as a predictor of both suicidal ideation and separation anxiety. We also highlighted sex differences in these associations, with attachment to father being a predictor of separation anxiety for both girls and boys, and attachment to mother being a predictor of separation anxiety essentially for boys. Considering suicidal ideation, attachment to father had direct effects across the sexes, but attachment to mother only had direct effects for girls. A significant association had previously been found between insecure attachment and internalizing problems, such as 
title: Suicidal ideation and affective insecurity during adolescence

suicidality or anxiety disorders during the adolescent period (Groh et al., 2012; Madigan et al., 2012). Results from the current study showed that maternal Alienation and paternal Trust were significant predictors of attachment. In particular, having psychologically controlling parents may lead to problems for adolescents in dealing with the separation-individuation process (Soenens \& Vansteenkiste, 2010). The findings of this exploratory study also suggested that male adolescents' suicidal thoughts are largely explained by maternal and paternal Alienation, and Distress at being away from a secure base. These results raise several key issues that are worth emphasizing here. First, they support the hypothesis that paternal bonds are more important to the adolescent development of sons than of daughters (Cero et al., 2013; Sheftall et al., 2013). Negative affective/cognitive experience of trust in the availability, accessibility and responsiveness of the father to their emotional need states (Armsden et al., 1987) has been found to predict more suicidal ideation among males. At the same time, maternal Alienation plays a major role in suicidal ideation. Alienation refers to

emotional and behavioral withdrawal (e.g., feelings of anger, hopelessness or interpersonal alienation). In line with Manassis (2001), we hypothesized that adolescents who perceive themselves to be rejected or alienated by their mothers (i.e., experiences of isolation, resentment, anger, and detachment) may limit their social contacts, acquire fewer coping skills for social situations, and develop anxiety in the social context of school, leading to school phobia. Second, the School phobia dimension, which reflected separation anxiety rather than a phobic reaction to school, was a major predictor of suicidal ideation for girls, while for boys it had only a minor influence. Other dimensions of separation anxiety, especially Distress at being away from a secure base, were more significant for boys. These results, though limited, suggested excessive anxiety concerning separation from attachment 
title: Suicidal ideation and affective insecurity during adolescence

figures for boys (affective source), and excessive anxiety about school (social source) for girls who had more suicidal ideas. These results suggest that boys who experienced elevated preoccupation or emotional distress about affective security showed more internalizing symptoms, such as suicidal ideation, whereas girls who expressed negative attitudes toward school had more suicidal thoughts. Thus, from an attachment perspective, female adolescent suicidal ideation is more an expression of anger about an unavailable attachment to the mother and school distress. Male adolescent suicidal ideation occurs more in response to a dysfunctional attachment to the father and a lack of success in achieving feelings of security far from a secure base.

The hypothesis that separation anxiety mediates the link between adolescent-parent attachment and suicidal ideation was partially supported (H3). The mediation pathway was confirmed for attachment to mother for girls and boys, although the direct pathways were also evident. Partial mediation was also confirmed for attachment to father for boys. Given the nonsignificant pathway from attachment to father to separation anxiety for girls, the mediated pathway to suicidal ideation was nonsignificant. More research is needed on mediation

processes, such as those involving separation anxiety, that might explain associations between insecure attachment and mental health. Our exploratory study yielded initial indications that separation anxiety can be a vulnerability factor in the formation of suicidal ideation in adolescence, specifically for boys with insecure attachment. Relationships with both parents may be important in the development of vulnerability for suicidal ideation, as they may lead to separation anxiety. Insecure attachment may increase adolescents' sensitivity to feeling defeated and trapped (psychological state), thereby increasing the likelihood of suicidal thoughts (Zortea et al., 2019). By demonstrating mediational pathways between adolescent 
title: Suicidal ideation and affective insecurity during adolescence

relationships with parents and suicidal ideation via separation anxiety, the current study sheds light on developmental vulnerability to suicidality. More specifically, providing they are replicated, our findings underscore the importance of considering secure relationships with both parents as potentially important factors for reducing the risk of adolescents engaging in suicidal ideas.

\section{Limitations}

Several limitations should be borne in mind. First, the sample was made up solely of French adolescents, which may reduce the generalizability of these findings. Given the small size of the sample, the overrepresentation of females, and the limited age range, our overall results should be regarded solely as preliminary findings to be confirmed by future research. The small size of our sample prevented the optimum use of regression analysis for sex, owing to the limited statistical power. In addition, this sample was composed solely of adolescents who had both male and female parent figures. Different family constellations (i.e., gay father families, lesbian mother families) would be important to consider in future studies. A larger sample could also test the effect of parental dyad insecurity (e.g., father-secure mother versus father-insecure mother). Furthermore, the self-report questionnaires reflected a subjective perception influenced by social desirability, and a multimethod approach would be preferable

(e.g., semistructured interview, data from parents, categorical standardized diagnoses, etc.). Finally, the cross-sectional nature of these data restricted our ability to test causal relations and to understand the mechanisms behind the path leading from affective insecurity to suicidal ideation. It might be useful to replicate this research in another cultural context, to examine whether these interactions are culturally specific. Future research should consider both larger samples and clinical samples, in order to determine whether differences in suicide 
title: Suicidal ideation and affective insecurity during adolescence

severity can be attributed to psychological comorbidity (e.g., depressive symptomology, general symptoms of anxiety) and suicidal behaviors. Additional research is needed to determine cognitive and emotional vulnerability factors for the risk of suicidal ideation among insecurely attached individuals.

\section{Conclusion}

The findings of this study strongly suggest that poor quality of parent-adolescent bonds induces separation anxiety in adolescents, rendering them vulnerable to psychological disturbances, such as suicidal thoughts. It is important to consider attachment as multifactorial, in that specific insecure attachment patterns may be associated with specific separation anxiety symptoms. Because of their concomitant effects, exploring both subjective separation anxiety and attachment as a function of sex differences in their symptomatic expression seems a promising way of developing an understanding of suicidal ideation among adolescents. Future research and etiological models of adolescent suicidality will need to identify parent-child attachment patterns and specific separation anxiety symptoms as possible risk factors for the development of suicidal ideation, and differentiate between the roles of each parent. If our initial results are confirmed by more extensive studies, attachmentfocused interventions or (multi)systemic family therapies targeting interventions in mother/father-son/daughter dyads might help to reduce suicidal ideation in adolescents. Individual psychotherapy to address suicidal symptoms could be effectively combined with

family therapy, social skills training, and peer support activities to promote more adaptive attachments and develop alternative secure attachments to peers. Adding the facets of attachment and separation anxiety to the assessment battery could also be useful to clinicians as potentially important predictors of adolescent adjustment and suicidality. 
title: Suicidal ideation and affective insecurity during adolescence

Conflict of Interest: The authors declare that they have no conflict of interest.

\section{References}

Achtergrade, S., Müller, J. M., Postert, C., Wessing, I., Mayer, A., \& Romer, G. (2015). Der Zusammenhang von Bindungsmustern und der Entwicklung von Angstsymptomen im Kindes- und Jugendalter. [Attachment patterns and their relation to the development of anxiety symptoms in childhood and adolescence]. Praxis der Kinderpsychologie und Kinderpsychiatrie, 64, 496-526. doi:10.13109/prkk.2015.64.7.496.

Adams, K. S., Sheldon-Keller, A. E., \& West, M. (1996). Attachment organisation and history of suicidal behaviour in clinical adolescents. Journal of Consulting and Clinical Psychology, 64, 264-272. doi:10.1037//0022-006x.64.2.264

Ainsworth, M. S. (1979). Infant-mother attachment. American Psychologist, 34, 932-937

Allen, J. P., \& Hauser, S. T. (1994). Autonomy and relatedness in family interactions as predictors of expressions of negative adolescent affect. Journal of Research on Adolescence, 4, 535-552.

Aquilino, W. S. (1997). From adolescent to young adults: A prospective study of parent-child relations during the transition to adulthood. Journal of Marriage and Family, 59, 670686. doi: $10.2307 / 353953$

American Psychiatric Association (APA) (2013). Diagnostic and statistical manual of mental disorders (5th ed.). American Psychiatric Association. 
title: Suicidal ideation and affective 1ısecurity during adolescence

Armsden, G. C., \& Greenberg, M. T. (1987). The inventory of parent and peer attachment: Individual differences and their relationship to psychological well-being in adolescence. Journal of Youth and Adolescence, 16, 427-454. doi:10.1007/BF02202939

Beyers, W., Gossens, L., Vansant, I., \& Moors, E. (2003). A structural model of autonomy in middle and late adolescence: Connectedness, separation, detachment, and agency. Journal of Youth and Adolescence, 32, 351-365. doi:10.1023/A:1024922031510

Blos, P. (1971). Les adolescents. Essai de psychanalyse. Stock.

Boeninger, D. K., Masyn, K. E., \& Conger, R. D. (2013). Testing alternative explanations for the associations between parenting and adolescent suicidal problems. Journal of Research on Adolescence, 23, 331-344. doi:10.1111/jora.12015

Booth-LaForce, C., Groh, A. M., Burchinal, M. R., Roisman, G. I., Owen, M. T., Cox, M. J. (2014). Caregiving and contextual sources of continuity and change in attachment security from infancy to late adolescence. Monographs of the Society for Research in Child Development, 79, 67-84. doi:10.1111/mono.12114

Bowlby, J. (1969). Attachment and loss: Vol. 1. Attachment. Basic.

Bowlby, J. (1976). Attachment and loss: Vol. 2. Separation anxiety and anger. Basic.

Brandibas, G., Sudres, J.-L., Gaspard, J.-L., \& Jeunier, B. (2010). Evaluer l'anxiété de séparation de l'adolescent avec le Separation Anxiety Symptom Inventory (SASI). Adaptation et validation française [Assess separation anxiety with Separation Anxiety Symptom Inventory (SASI). French adaptation and validation]. Neuropsychiatrie de l'enfance et de l'adolescence, 58, 480-487. doi:10.1016/j.neurenf.2010.07.004

Bretherton, I. (1985). Attachment theory: Retrospect and prospect. Monographs of the Society for Research in Child Development, 50, 3-35.

Page 26 of 41

Bridge, J. A., Goldstein, T. R., \& Brent, D. A. (2006). Adolescent suicide and suicidal behavior. Journal of Child Psychology and Psychiatry, 47, 372-394. doi:10.1111/j.1469-7610.2006.01615.x

Brumariu, L. E., \& Kerns, K. A. (2010a). Parent-child attachment and internalizing symptoms in childhood and adolescence: A review of empirical findings and future directions. Development and Psychopathology, 22, 177-203. doi:10.1017/S0954579409990344

Brumariu, L. E., \& Kerns, K. A. (2010b). Mother-child attachment patterns and differenrs types of anxiety symptoms: Is there specificty of relations? Child Psychiatry and Human Development, 41, 663-674. doi:10.1007/s10578-010-0195-0

Byrne, B. M. (2013). Structural equation modeling with AMOS: Basic concepts, applications, and programming. Routledge.

Cero, I., \& Sifers, S. K. (2013). Parenting beahvior and the Interpersonal-Psychological Theory of suicide: A mediated moderation analysis with adolescents. Journal of Affective Disorders, 150, 987-992. doi:10.1016/j.jad.2013.05.025

Chin, W. W. (1998). The partial least squares approach for structural equation modeling. In G. A. Marcoulides (Ed.), Methodology for business and management. Modern methods for business research (p. 295-336). Lawrence Erlbaum Associates. 
title: Suicidal idtaul and affective insecurity during adolescence

Chin, W.W. (2010) How to write up and report PLS analyses. In V. Esposito Vinzi, W. W. Chin, J. Henseler, \& H. Wang (Eds.), Handbook of partial least squares: Concepts, methods and applications (pp. 655-690). Springer.

Colonnesi, C., Draijer, E. M., Stams, J. J. M., Van der Bruggen, C. O., Bögels, S. M., \& Noom, M. J. (2011). The relation between insecure attachment and child anxiety: A meta-analytic review. Journal of Clinical Child and Adolescent Psychology, 40, 630-645. doi:10.1080/15374416.2011.581623

Connor, J., \& Rueter, M. A. (2006). Parent-child relationships as system of support or risk for adolescent suicidality. Journal of Family Psychology, 20, 143-155. doi:10.1037/08933200.20.1.143

Daniel, S. S., \& Goldston, D. B. (2009). Interventions for suicide youth: A review of the litterature and developmental considerations. Suicide and Life-Threatening Behavior, 39, 252-268. doi:10.1521/suli.2009.39.3.252 de Jong, M. L. (1992). Attachment, individuation, and risk of suicide in late adolescence. Journal of Youth and Adolescence, 21, 357-373. doi:10.1007/BF01537023

Demirdis, E., \& Celik, S. B. (2013). Separation anxiety inventory: Validity and reliabilty study. Procedia-Social and Behavioral Sciences, 84, 1727-1731. doi:10.1016/j.sbspro.2013.07.021

Duchesne, S., \& Ratelle, C. (2014). Attachment security to mothers and fathers and the developmental trajectories of depressive symptoms in adolescence: Which parent for which trajectory? Journal of Youth and Adolescence, 43, 641-654. doi:10.1007/s10964-013-0029-z

Eliezer, K., Yahav, R., \& Hen, K. O. (2012). The internalization of the "father" object among young men and its relation to separation-individuation patterns, anxiety and depression. Child and Adolescent Social Work Journal, 29, 323-344.

Ewing, E. S., Diamond, G., \& Levy, S. (2015). Attachment-based family therapy for depressed and suicidal adolescents: Theory, clinical model and empirical support.

Attachment and Human Development, 17, 136-156. doi:10.1080/14616734.2015.1006384

Falk, R. F., \& Miller, N. B. (1992). A primer for soft modeling. University of Akron Press.

Feldman, M., \& Wilson, A. (1997). Adolescent suicidality in urban minorities and its relationships to conduct disorders, depression and separation anxiety. Journal of the American Academy of Child and Adolescent Psychiatry, 36, 75-84. doi:10.1097/00004583-199701000-00020

Flouri, E., \& Buchanan, A. (2003). The role of father involvement and mother involvement in adolescents' psychological well-being. British Journal of Social Work, 33, 399-406. doi:10.1093/bjsw/33.3.399

Fornell, C., \& Cha, J. (1994). Partial least squares. Advanced Methods of Marketing Research, 407, 52-78.

Frank, S. J., Pirsch, L. A., \& Wright, V. C. (1990). Late adolescents' perceptions of their 
title: Suicidal ideation and affective insecurity during adolescence

relationships with their parents: Relationships among deidealization, autonomy, relatedness, and insecurity and implications for adolescent adjustement and ego identity status. Journal of Youth and Adolescence, 19, 571-588. doi:10.1007/BF01537177

Frey, L. L., Beesley, D., \& Miller, M. R. (2006). Relational health, attachment, and psychological distress in college women and men. Psychology of Women Quaterly, 30, 303-311. doi:10.1111/j.1471-6402.2006.00298.x

Geuzaine, C., Debry, M., \& Liesens, V. (2000). Separation from parents in late adolescence: The same for boys and girls? Journal of Youth and Adolescence, 29, 79-91.doi:10.1023/A:1005173205791

Gould, M. S., King, R., Greenwald, S., Fisher, P., Schwab-Stone, M., Kramer, R., Flisher, A. J., Goodman, S., Canino, G., \& Shaffer, D. (1998). Psychopathology associated with suicidal ideation and attempts among children and adolescents. Journal of the American Academy of Child \& Adolescent Psychiatry, 37, 915-923. doi:10.1097/00004583-199809000-00011

Gouveia-Pereira, M., Abreu, S., \& Martins, C. (2014). How do families of adolescents with suicidal ideation behave? Psicologia: reflexao e critica, 27, 171-178. doi:10.1590/S0102-79722014000100019

Groh, A. M., Roisman, G I., Booth-LaForce, C., Fraley, R C., Owen, M. T., Cox, M. J., \& Burchinal, M. R. (2014). Stability of attachment security from infancy to late adolescence. Monographs of the Society for Research in Child Development, 79, 5166. doi:10.1111/mono.12113

Groh, A. M., Roisman, G. I., van Ijzendoorn, M. H., Bakermans Kranenburg, M. J., \& Fearon, R. (2012). The significance of insecure and disorganized attachment for children's internalizing symptoms: A meta-analytic study. Child Development, 83, 591-610. doi:10.1111/j.1467-8624.2011.01711.x

Guarnieri, S., Ponti, L., \& Tani, F. (2010). The Inventory of Parent and Peer Attachment (IPPA): A study on the validity of styles of adolescent attachment to parents and peers in an Italian sample. TPM-Testing, Psychometrics, Methodology in Applied Psychology, 17, 103-130.

Gullone, E., \& Robinson, K. (2005). The Inventory of Parent and Peer Attachment-Revised for children: A psychometric investigation. Clinical Psychology and Psychotherapy, 12, 67-79. doi:10.1002/cpp.433

Hair, J. F., Hult, G. T. M., Ringle, C. M., \& Sarstedt, M. (2017). A primer on partial least squares structural equation modeling (PLS-SEM) ( $2 d$ ed). Sage.

Hair, J. F., Sarstedt, M., Ringle, C. M., \& Gudergan, S.P. (2018). Advanced issues in partial least squares structural equation modeling (PLS-SEM). Sage.

Hill, R. M., Castellanos, D., \& Pettit, J. W. (2011). Suicide-related behaviors and anxiety in children and adolescents: A review. Clinical Psychology Review, 31, 1133-1144. doi:10.1016/j.cpr.2011.07.008 
title: Suicidal ideation and affective insecurity during adolescence

Hock, E., Eberly, M., Bartle-Haring, S., Ellwanger, P., \& Widaman, K. (2001). Separation anxiety in parents of adolescents: Theoretical significance and scale development. Child Development, 72, 284-298. doi:10.1111/1467-8624.00279

Hoeve, M, Dubas, J. S., Gerris, J. R. M., van der Laan, P. H., \& Smeenk, W. (2011). Maternal and paternal parenting styles: Unique and combined links to adolescent and early adult delinquency. Journal of Adolescence, 34, 813-827.

doi:10.1016/j.adolescence.2011.2.004

Holmbeck, G., \& Leake, C. (1999). Separation-individuation and psychological adjustment in late adolescence. Journal of Youth and Adolescence, 28, 563-581. doi:10.1023/A:1021654626328

Hu, L., \& Bentler, P. M. (1999). Cutoff criteria for fit indexes in covariance structure analysis: Conventional criteria versus new alternatives. Structural Equation Modeling: A Multidisciplinary Journal, 6, 1-55. doi:10.1080/10705519909540118

Jones, J. D., Brett, B. E., Ehrlich, K. B., Lejuez, C. W., \& Cassidy, J. (2014). Maternal attachment style and responses to adolescents' negative emotions: The mediating role of maternal emotion regulation. Parenting, Science and Practice, 14, 235-257. doi:10.1080/15295192.2014.972760

Jones, J. D., Fraley, R. C., Ehrlich, K. B., Stern, J. A., Lejuez, C. W., Shaver, P. R., \& Cassidy, J. (2018). Stability of attachment style in adolescence: An empirical test of alternative developmental processes. Child Development, 89, 871-880. doi:10.1111/cdev.12775

Kaplan, B. L. (1978). Perspectives on early adolescence. Clinical Social Work Journal, 6, 108-122.

Kaplan, J. K., \& Worth, S. A. (1993). Individuation-attachment and suicide trajectory: A developmental guide for the clinician. OMEGA-Journal of Death and Dying, 27, 207-237. doi:10.2190/80QD-UTH6-93KH-G22V

Kins, E., Beyers, W., \& Soenens, B. (2012). When the separation-individuation process goes awry: Distinguishing between dysfunctional dependence and dysfunctional independence. International Journal of Behavioral Development, 37, 1-12. doi:0.1177/0165025412454027

Kins, E., Soenens, B., \& Beyers, W. (2011). "Why do they have to grow up so fast?" Parental separation anxiety and emerging adults' pathology of separation-individuation. Journal of Clinical Psychology, 67, 647-664. doi:10.1002/jclp.20786

Koehn, A. J., \& Kerns, K. A. (2018). Parent-child attachment: Meta-analysis of associations with parenting behaviors in middle childhood and adolescence. Attachment \& Human Development, 20, 378-405. doi:10.1080/14616734.2017.1408131

Koepke, S., \& Denissen, J. J. A. (2012). Dynamics of identity development and separationindividuation in parent-child relationships during adolescence and emerging adulthood - a conceptual integration. Developemental Review, 32, 67-88. doi:10.1016/j.dr.2012.01.001 
title: Suicidal ideation and affective insecurity during adolescence

Kroger, J. (1998). Adolescence as a second separation-individuation process: Critical review of an object relations approach. In E. Skoe \& V. d. Lippe (Eds.), Personality development in adolescence: A cross-national and life span perspective (pp. 172-192). Routledge.

Kroger, J., \& Haslett, S. J. (1988). Separation-individuation and ego identity status in late adolescence: A two-year longitudinal study. Journal of Youth and Adolescence, 17, 59-79. doi:10.1007/BF01538724

Lamb, M. E. (1975). Fathers: Forgotten contributors to child development. Human Development, 18, 245-266.

Lapsley, D. K., \& Edgeron, J. (2002). Separation-individuation, adult attachment style, and college adjustment. Journal of Counseling and Development, 80, 484-492. doi:10.1002/j.1556-6678.2002.tb00215.x

Leguina, A. (2015). A primer on partial least squares structural equation modeling (PLSSEM). International Journal of Research \& Method in Education, 38, 220-221. doi:10.1080/1743727X.2015.1005806

Lessard, J. C., \& Moretti, M. M. (1998). Suicidal ideation in an adolescent clinical sample: Attachment patterns and clinical implications. Adolescence, 21, 383-395. doi:10.1006/jado.1998.0169

Lewinsohn, P. M., Rohde, P., \& Seeley, J. R. (1996). Adolescent suicidal ideation and attempts: Prevalence, risk factors, and clinical implications. Clinical Psychology: Science and Pratice, 40, 25-40. doi:10.1111/j.1468-2850.1996.tb00056.x

Lobo Prabhu, S., Molinari, V., Bowers, T., \& Lomax, J. (2010). Role of the family in suicide prevention: An attachment and family systems perspective. Bulletin of the Menninger Clinic, 74, 301-327. doi:10.1521/bumc.2010.74.4.301

Mabilia, D., Di Riso, D., Lis, A., \& Bobbio, A. (2019). A prediction model for separation anxiety: The role of attachment styles and internalizing symptoms in Italian young adults. Journal of Adult Development, 26, 286-294. doi:10.1007/s10804-019-09327-y

Madigan, S., Atkinson, L., Laurin, K., \& Benoit, D. (2013). Attachment and internalizing behavior in early childhood: A meta-analysis. Developmental Psychology, 49, 672-689. doi:10.1037/a0028793

Manassis, K. (2001). Child-parent relations: Attachment and anxiety disorders. In W. K. Silverman and A. P. Field (Eds.), Anxiety disorders in children and adolescents (pp. 280-298). Cambridge University Press.

Mattanah, J. F., Hancock, G. R., \& Brand, B. L. (2004). Parental attachment, separationindividuation, and college student adjustment: A structural equation analysis of mediational effects. Journal of Counseling Psychology, 51, 213-225. doi:10.1037/0022-0167.51.2.213

Mayseless, O., Danieli, R., \& Sharabany, R. (1996). Adults' attachment patterns and coping with separation. Journal of Youth and Adolescence, 25, 667-690.

doi:10.1007/BF01537360 
title: Suicidal ideation and affective insecurity during adolescence

Mayseless, O., \& Scharf, M. (2009). Too close for comfort: Inadequate boundaries with parents and individuation in late adolescent girls. American Journal of Orthopsychiatry, 79, 191-202. doi: 10.1037/a0015623

Meeus, W., Iedema, J., Maassen, G., \& Engels, R. (2005). Separation-individuation revisited: On the interplay of parent-adolescent relations, identity and emotional adjustment in adolescence. Journal of Adolescence, 28, 89-106. doi:10.1016/j.adolescence.2004.07.003

Milan, S., Zona, K., \& Snow, S. (2013). Pathways to adolescent internalizing: Early attachment insecurity as a lasting source of vulnerability. Journal of Clinical Child and Adolescent Psychology, 42, 371-383. doi:10.1080/15374416.2012.736357

Miranda, R., \& Shaffer, D. (2013). Understanding the suicidal moment in adolescence. Annals of the New York Academy of Sciences, 1304, 14-21. doi:10.1111/nyas.12291

Ponappa, S., Bartle-Haring, S., \& Day, R. (2014). Connection to parents and healthy separation during adolescence: A longitudinal perspective. Journal of Adolescence, 37, 555-566. doi:10.1016/j.adolescence.2014.04.005

Potard, C., Kubiszewski, V., Gimenes, G., \& Courtois, R. (2014). Validation of the French version of the Suicidal Ideation Questionnaire among adolescents. Psychiatry

Research, 215, 471-476. doi:10.1016/j.psychres.2013.11.025

Quintana, S. M., \& Kerr, J. (1993). Relational needs in late adolescent separation individuation. Journal of Counseling and Development, 71, 349-354. doi:10.1002/j.1556-6676.1993.tb02225.x

Reinherz, H. Z., Tanner, J. L., Berger, S. R., Beardslee, W. R., \& Fitzmaurice, G. M. (2006). Adolescent suicidal ideation as predictive of psychopatholgy, suicidal beahvior, and compromised functioning at age 30. American Journal of Psychiatry, 163, 1226-1232. doi:10.1176/appi.ajp.163.7.1226

Roberto, A. J., Carlyle, K. E., Goodall, C. E., \& Castle, J. D. (2009). The relationship between parents' verbal aggressiveness and responsiveness and young adult children's attachment style and relational satisfaction with parents. Journal of Family Communication, 9, 90-106. doi:10.1080/15267430802561659

Ruhl, H., Dolan, E. A., \& Buhrmester, D. (2015). Adolescent attachment trajectories with mothers and fathers: The importance of parent-child relationship experience and gender. Journal of Research on Adolescence, 25, 427-442. doi:10.1111/jora.1244

Russel, A., \& Saebel, J. (1997). Mother-son, mother-daughter, father-son, and fatherdaughter: Are they distinct relationships? Developmental Review, 17, 111-147. doi:10.1006/drev.1996.0431

Sandhu, R. (2014). Father attachment predicts adolescent girls' social and emotion development. Doctoral thesis, Antioch University, Seattle.

Scharf, M., Mayseless, O., \& Kivenson-Baron, I. (2004). Adolescents' attachment representations and developmental tasks in emerging adulthood. Developmental Psychology, 40, 430-444. doi:10.1037/0012-1649.40.3.430

Page 31 of 41 
title: Suicidal ideation and affective insecurity during adolescence

Schimmenti, A., \& Bifulo, A. (2015). Linking lack of care in childhood to anxiety disorders in emerging adulthood: The role of attachment styles. Child and Adolescent Mental Health, 20, 41-48. doi:10.1111/camh.12051

Sheftall, A. H., Mathias, C. W., Furr, R. M., \& Dougherty, D. M. (2013). Adolescent attachment security, family functioning, and suicide attempts. Attachment and Human Development, 15, 368-383. doi:10.1080/14616734.2013.782649

Soenens, B., \& Vansteenkiste, M. (2010). A theoretical upgrade of the concept of parental psychological control: Proposing new insights on the basis of self-determination theory. Developmental Review, 30, 74-99. doi:10.1016/j.dr.2009.11.001

Steinberg, L. (1987). Recent research on the family at adolescence: The extent and nature of sex differences. Journal of Youth and Adolescence, 16, 191-197. doi:10.1007/BF02139090

Stepp, S. D., Morse, J. Q., Yaggi, K. E., Reynolds, S. K., Reed, L. I., \& Pikonis, P. A. (2010). The role of attachment styles and interpersonal problems in suicide-related behaviors. Suicide and Life-Threatening Behavior, 38, 592-607. doi:10.1521/suli.2008.38.5.592

Stolz, H. E., Barber, B. K., \& Olsen, J. A. (2005). Toward disentangling fathering and mothering: An assessment of relative importance. Journal of Marriage and Family, 67, 1076-1092. doi:10.1111/j.1741-3737.2005.00195.x

Strauss, J., Birmaher, B., Bridge, J., Axelson, D., Chiappetta, L., Brent, D., \& Ryan, N. (2000). Anxiety disorders in suicidal youth. Canadian Journal of Psychiatry, 45, 739745. doi:10.1177/070674370004500807

UNICEF (2014). Ecoutons ce que les enfants ont à nous dire. Adolescents en France: le grand malaise [Let us listen to what children have to say. Teenagers in France: the great malaise]. UNICEF.

Vander Stoep, A., McCauley, E., Flynn, C., \& Stone, A. (2009). Thoughts of death and suicide in early adolescence. Suicide and Life-Threatening Behavior, 39, 599-613. doi:10.1521/suli.2009.39.6.599

Vignoli, E., \& Mallet, P. (2004). Validation of a brief measure of adolescents' parent attachment based on Armsden and Greenberg's three-dimension model. European Review of Applied Psychology, 54, 251-260. doi:10.1016/j.erap.2004.04.003

Vivona, J. M. (2000). Parental attachment styles of late adolescents: Qualities of attachment relationships and consequences for adjustment. Journal of Counseling Psychology, 47, 316-329. doi:10.1037/0022-0167.47.3.316

WHO (2014). Preventing suicide: A global imperative. World Health Organization.

Williams, L. J., Vandenberg, R. J., \& Edwards, J. R. (2009). 12 structural equation modeling in management research: A guide for improved analysis. Academy of Management Annals, 3, 543-604. doi:10.5465/19416520903065683

Woodward, L., Fergusson, D. M., \& Belsky, J. (2000). Timing of parental separation and attachment to parents in adolescence: Results of a prospective study from birth to age 16. Journal of Marriage and Family, 62, 162-174. doi:10.1111/j.17413737.2000.00162.x

Zortea, T. C., Dickson, A., Gray, C. M., \& O’Connor, R. C. (2019). Associations between experiences of disrupted attachments and suicidal thoughts and behaviours: An 
title: Suicidal ideation and affective insecurity during adolescence

interpretative phenomenological analysis. Social Science \& Medicine, 235, 112408.

doi:10.1016/j.socscimed.2019.112408

Page 33 of 41

\section{Figures to be inserted}

Figure 1:

Mediational hypothesis of separation anxiety in the relationship between attachment and suicidal ideation 
title: Suicidal ideation and affective insecurity during adolescence

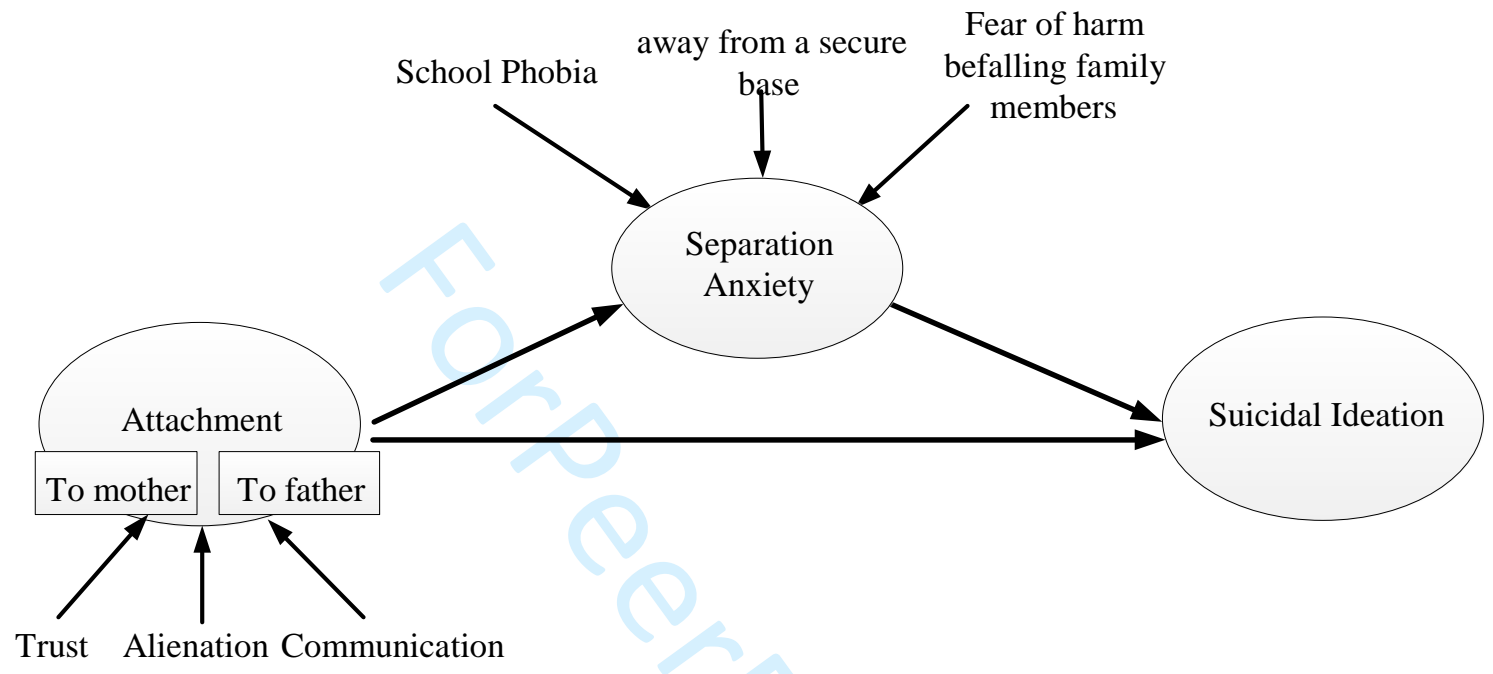

Page 34 of 41

Figure 2

Model of relations among attachment to mother, attachment to father, separation anxiety, and suicidal ideation for girls. 
title: Suicidal ideation and affective insecurity during adolescence

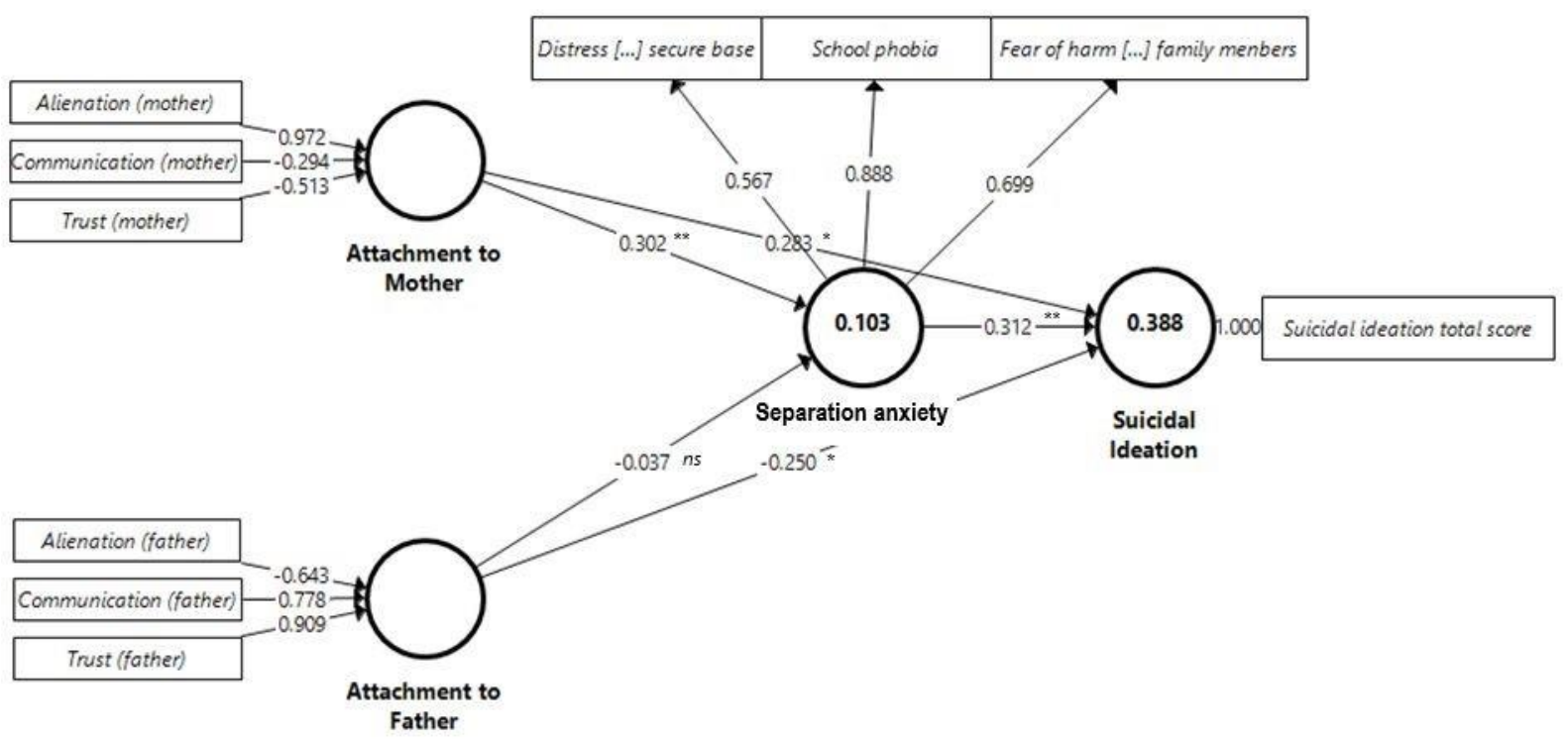

Note. Numbers are standardized coefficients. Numbers in bold are $R^{2}{ }^{*} p<.05$. ${ }^{*} * p<.01$. $n s$ : nonsignificant.

Figure 3

Model of relations among attachment to mother, attachment to father, separation anxiety, and suicidal ideation for boys. 
title: Suicidal ideation and affective insecurity during adolescence

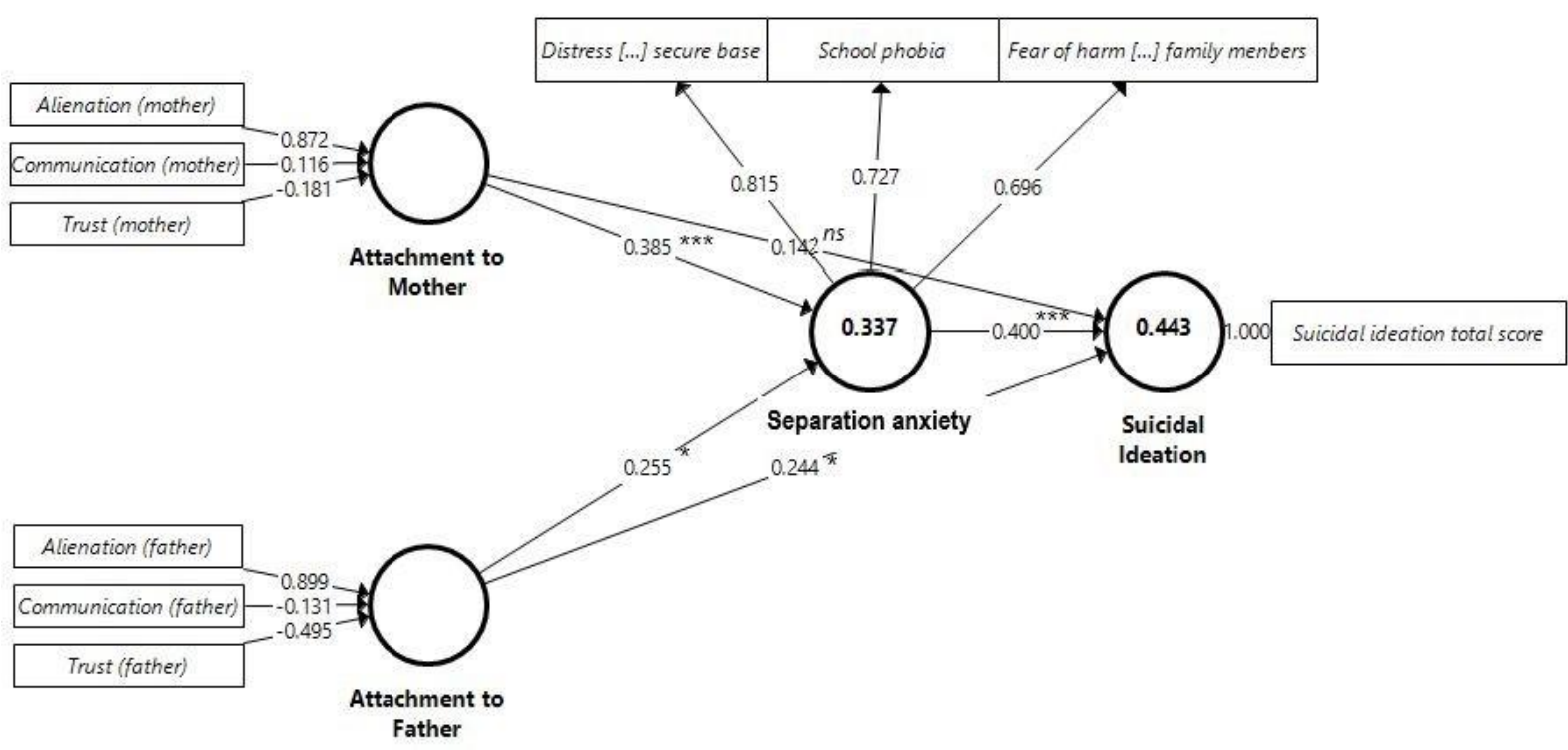

Note. Numbers are standardized coefficients. Numbers in bold are $R^{2}{ }^{*} p<.05 . * * * p<.001$. $n s$ : nonsignificant.

Table 1

$\begin{array}{ccc}\text { Secure } & \text { Ambivalent } & \text { Avoidant } \\ \text { attachment } & \text { attachment } & \text { attachment }\end{array}$

\begin{tabular}{cccccc}
\hline To mother & To father & To mother & To father & To mother & To father \\
\hline $62.8 \%$ & $57.1 \%$ & $17.3 \%$ & $11.9 \%$ & $19.6 \%$ & $29.5 \%$ \\
$(n=196)$ & $(n=178)$ & $(n=54)$ & $(n=37)$ & $(n=61)$ & $(n=92)$ \\
$67.7 \%$ & $64.5 \%$ & $18.3 \%$ & $18.3 \%$ & $14.0 \%$ & $17.2 \%$ \\
$(n=63)$ & $(n=60)$ & $(n=17)$ & $(n=17)$ & $(n=13)$ & $(n=16)$ \\
\hline
\end{tabular}


title: Suicidal ideation and affective insecurity during adolescence

Distribution of styles of attachment to mother and father 
title: Suicidal ideation and affective insecurity during adolescence

Page 37 of 41

Table 2

Mean scores and correlations between dimensions of attachment, separation anxiety, and suicidal ideation scores

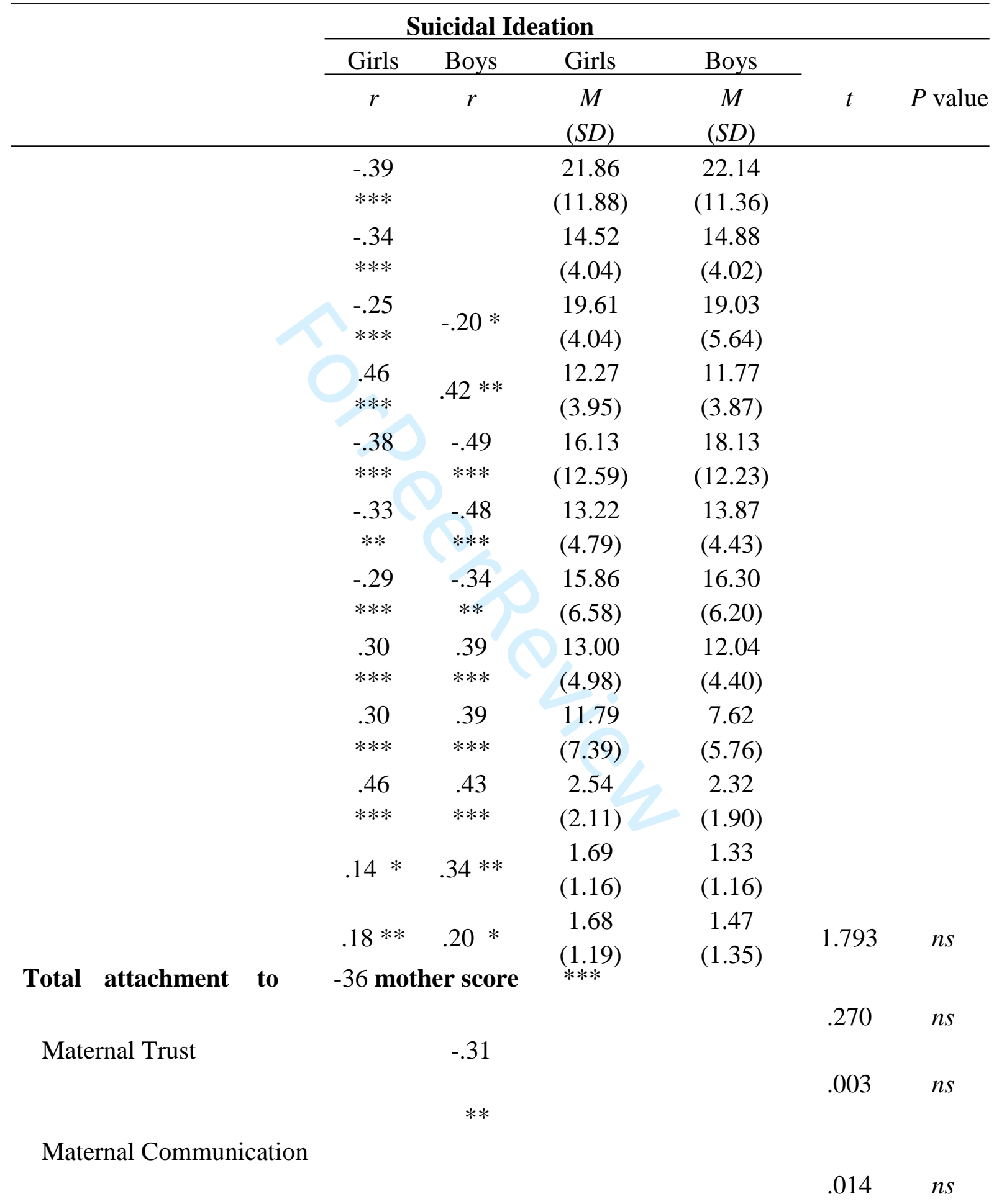


title: Suicidal ideation and affective insecurity during adolescence

Maternal Alienation

\section{Total attachment to father}

Paternal Trust

Paternal Communication

Paternal Alienation

\section{Total Separation anxiety}

$13.490 * * *$ score

School phobia 3.759

Fear related to secure base 7.028

Fear related to family members

Note. $* p<.05 . * * p<.01 . * * * p<.001 . n s:$ nonsignificant. 
Table 3

Comparison of mean and standard deviations for suicidal ideation and separation anxiety scores for the secure, ambivalent and avoidant attachment styles

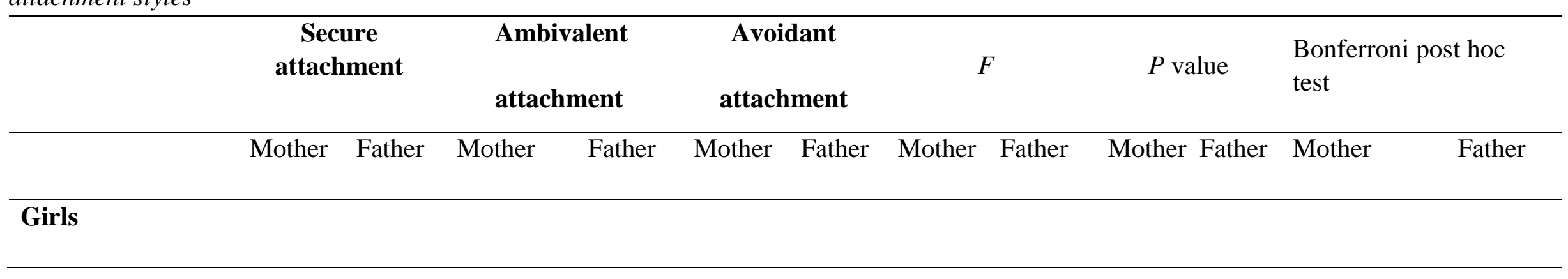




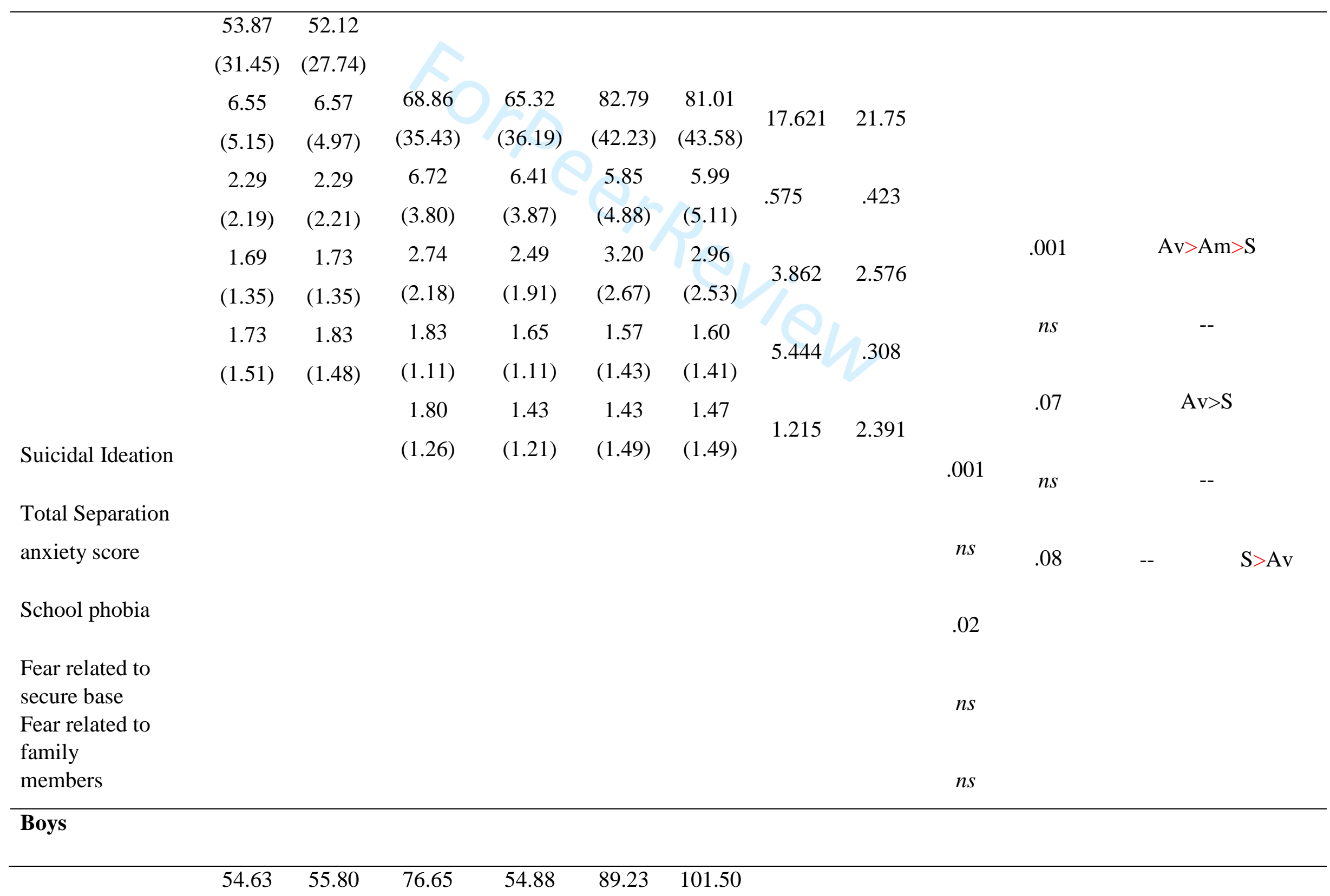




\begin{tabular}{|c|c|c|c|c|c|c|c|c|c|c|c|c|}
\hline Suicidal Ideation & (31.74) & $(33.76)$ & $(49.00)$ & $(15.02)$ & $(40.77)$ & $(50.69)$ & 6.144 & 11.486 & .003 & .001 & \multicolumn{2}{|c|}{$A v>A m>S$} \\
\hline Total Separation & 3.10 & 3.08 & 3.82 & 3.47 & 3.00 & 3.44 & & & & & & \\
\hline anxiety score & $(3.90)$ & $(3.88)$ & $(2.83)$ & $(2.75)$ & $(2.24)$ & (3.27) & .310 & .116 & $n s$ & $n s$ & & - \\
\hline \multicolumn{13}{|c|}{ anuscriptcentral.com/gnt } \\
\hline Page 39 of 41 & \multicolumn{12}{|c|}{ The Journal of Genetic Psychology - Under Review } \\
\hline & 1.81 & 1.80 & 2.53 & 2.00 & 3.00 & 3.38 & & & & & & \\
\hline School phobia & & & & & & & 2.73 & .746 & .07 & .01 & $\mathrm{Av}>\mathrm{S}$ & $A v>A m>S$ \\
\hline & $(1.92)$ & $(1.73)$ & $(1.87)$ & $(1.5$ & $(1.47)($ & $.39)$ & & & & & & \\
\hline \multirow[t]{2}{*}{ Fear related to } & 1.05 & 1.05 & 1.88 & 1.53 & 1.77 & 1.19 & & & & & & \\
\hline & & & & & & & 4.64 & .132 & .01 & $n s$ & $A m>A v>S$ & -- \\
\hline secure base & $(1.04)$ & $(1.03)$ & $(1.57)$ & \multicolumn{3}{|c|}{$(1.18)(.72)(1.56)$} & & & & & & \\
\hline
\end{tabular}




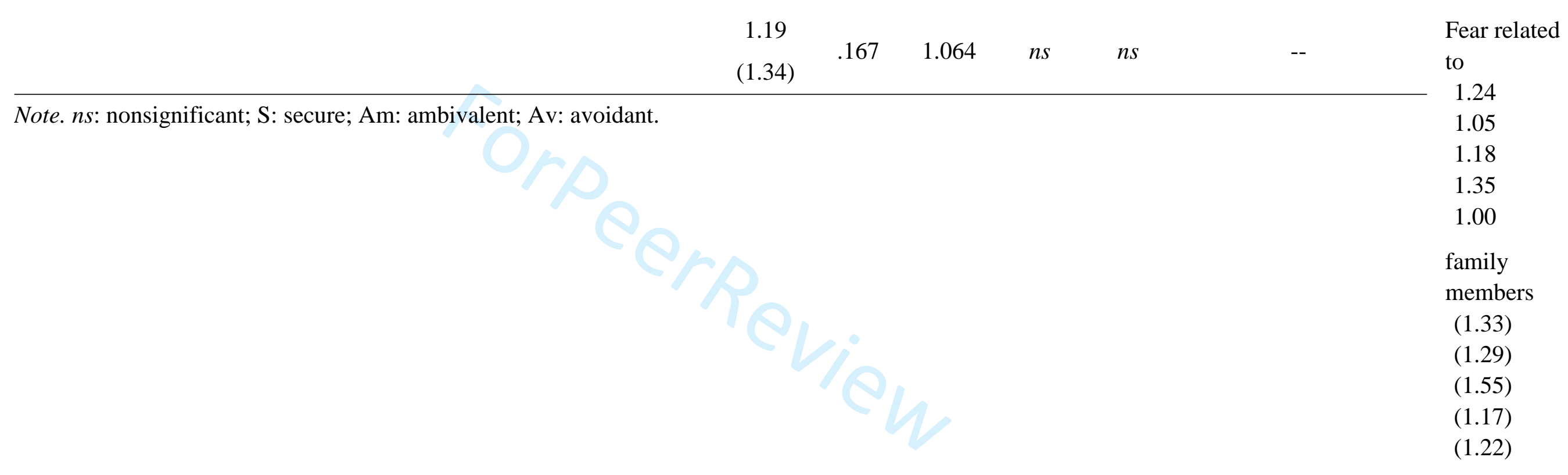


anuscriptcentral.com/gnt 
Table 4

Effect size $\left(f^{2}\right)$

Attachment to Father Separation Anxiety Suicidal Ideation

\begin{tabular}{cccc}
\hline Girls & Boys & Girls & Boys \\
\hline $\mathrm{f}^{2}$ & $\mathrm{f}^{2}$ & $\mathrm{f}^{2}$ & $\mathrm{f}^{2}$ \\
\hline .01 & .24 & .06 & .06 \\
.05 & .11 & .08 & .10 \\
& & .20 & .62
\end{tabular}


ttp://mc.manuscriptcentral.com/gnt 
Table 5

PLS regression results for mediation model

\begin{tabular}{|c|c|c|c|c|c|c|}
\hline \multirow[t]{2}{*}{ Hypothesis pathway } & \multicolumn{2}{|l|}{ Path coefficient } & \multicolumn{2}{|c|}{$T$ value } & \multicolumn{2}{|c|}{ Mediation strength } \\
\hline & Girls & Boys & Girls & Boys & Girls & Boys \\
\hline
\end{tabular}

\section{Direct effects without mediator}

$-.35$

Attachment to father $=>$ Suicidal ideation

Attachment to mother $=>$ Suicidal ideation

\section{Indirect effects}

Attachment to father $=>$ Separation anxiety $=>$ Suicidal ideation

Attachment to mother $=>$ Separation anxiety $=>$

Suicidal ideation 